\title{
Polyamines in dormancy breaking of tree seeds
}

\author{
Z. Szczotka and U. Lewandowska \\ Institute of Dendrology, Polish Academy of Sciences, Kornik, Poland
}

\section{Introduction}

Work connected with the role of polyamines in the physiology of dormancy breaking of Acer platanoides and Fraxinus excelsior seeds (in the initial stage) has proceeded in two directions: 1) studies of changes in the content of endogenous polyamines - putrescine, spermidine and spermine - during breaking of dormancy, and their possible interaction with changes in the activity of other fundamental metabolic indicators; 2) recognition of the influence of polyamines on seed dormancy breaking as compared to the influence of growth regulators and modifiers of polyamine metabolism.

\section{Materials and Methods}

Experiments were conducted on $A$. platanoides and $F$. excelsior seeds collected in the Kornik Arboretum. Conditions of storage, stratification and biochemical analysis were as reported in Szczotka (1984a, b). A. platanoides seeds were soaked before stratification in the following solutions: spermine, $50 \mathrm{mg} / \mathrm{l} ; \mathrm{GA}_{4 / 7}$, $50 \mathrm{mg} / \mathrm{l}$; kinetin, $50 \mathrm{mg} / \mathrm{l}$; spermine, 50 $\mathrm{mg} / \mathrm{l}+\mathrm{GA}_{4 / 7}, 50 \mathrm{mg} / \mathrm{l}$; spermine $50 \mathrm{mg} / \mathrm{l}+\mathrm{kine}$ tin $50 \mathrm{mg} / \mathrm{l} ; \beta$-hydroxyethylhydrazine, $100 \mathrm{mg} /$; methyglyoxal $100 \mathrm{mg} / \mathrm{l}$; and dicyclohexylammonium sulfate, $100 \mathrm{mg} / \mathrm{l}$. Stratification of $F$. excelsior seeds included 2 steps: 16 wk at $15^{\circ} \mathrm{C}$ and 16 wk at $3^{\circ} \mathrm{C}$. Seeds were soaked in spermine, $25 \mathrm{mg} / \mathrm{l}$, or $\mathrm{GA}_{4 / 7}, 50 \mathrm{mg} / \mathrm{l}$, before warm or cold stratification.

\section{Results}

We observed that changes in the level of polyamine in $A$. platanoides seeds were similar to the metabolism of proteins at the end of dormancy breaking and during germination (Szczotka and Tomaszewska 1979; Korcz et al., 1985) (Fig. 1).

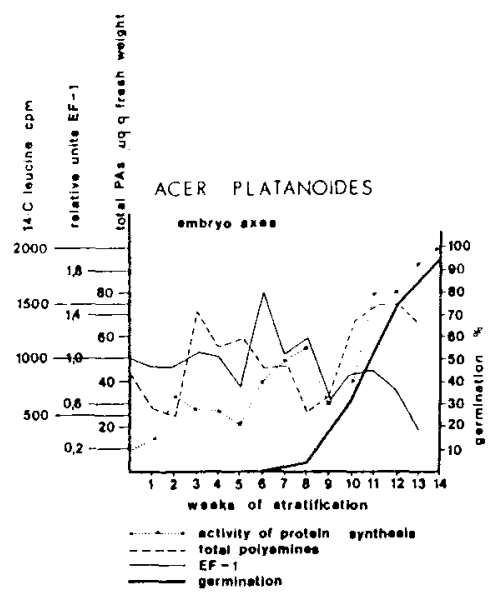

Fig. 1. Concentration of polyamines and activity of metabolism of proteins. 


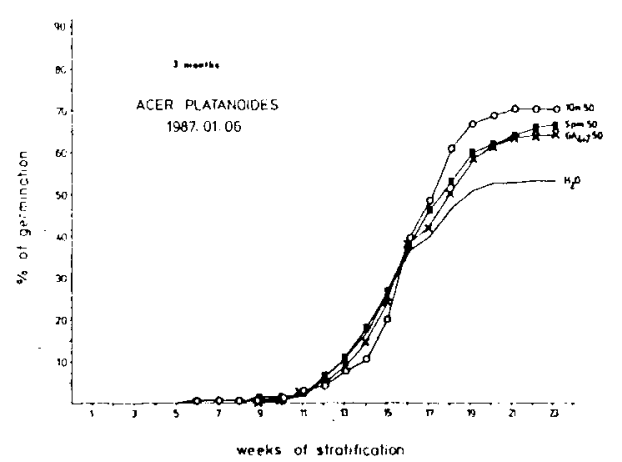

Fig. 2. Effect of kinetin, spermine and gibberellins 4 and 7 on dormancy breaking of $A$. platanoides seeds collected in 1986 after 3 mo of storage.

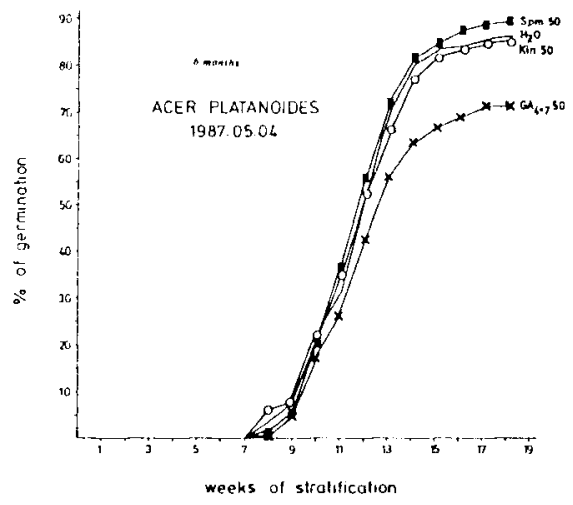

Fig. 3. Effect of kinetin, spermine and gibberellins 4 and 7 on dormancy breaking of $A$. platanoides seeds collected in 1986 after 6 mo of storage.

After the first 3 mo of storage when the seeds were in the state of deep dormancy, spermine (Spm), gibberellin (GA) and all modifiers of polyamine metabolism were active stimulators of dormancy breaking. The same was true for mixtures of spermine with kinetin (Kin), GA and all modifiers of polyamine metabolism (stratification period $23 \mathrm{wk}$ ) (Fig. 2).

After 6 mo of storage, when dormancy was partially broken, only spermine $\beta$ hydroxyethyihydrazine and dicyclohex- ylammonium sulfate stimulated germination. Other substances, such as $\mathrm{GA}_{4 / 7}$, were inhibitors (Fig. 3).

In the seed's collected in 1987, differences between the different solutions were insignificant. A weak stimulation of dormancy breaking was found during treatment with spermine, kinetin and $\beta$ hydroxyethylhydrazine. A strong inhibitory influence was observed with the remaining substances (Fig. 4).

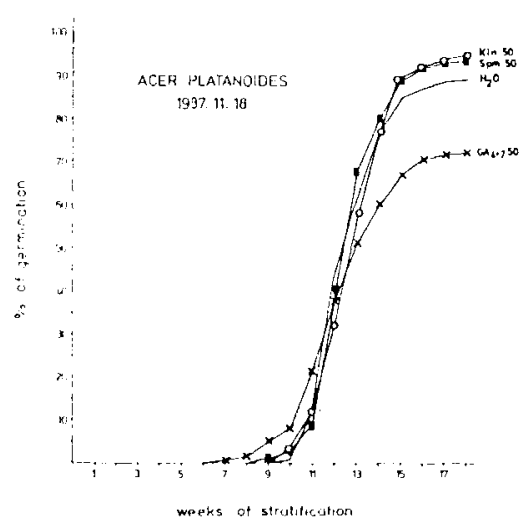

Fig. 4. Effect of kinetin. spermine and gibberellins 4 and 7 on dormancy breaking of A. platanoides seeds collected in 1987.

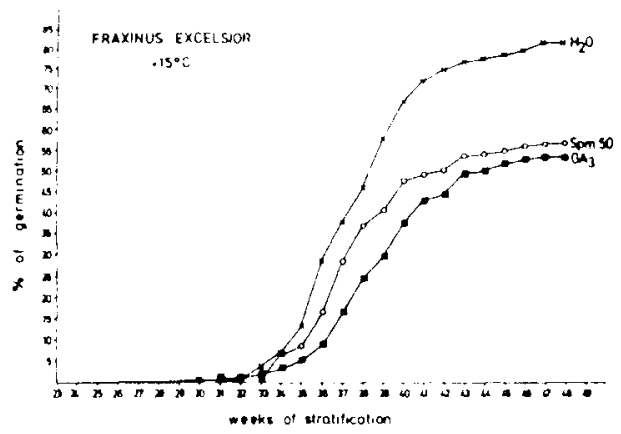

Fig. 5. Effect of spermine and gibberellic acid $\left(G A_{3}\right)$ on dormancy breaking of $F$. excelsior seeds. Application before warm phase. 


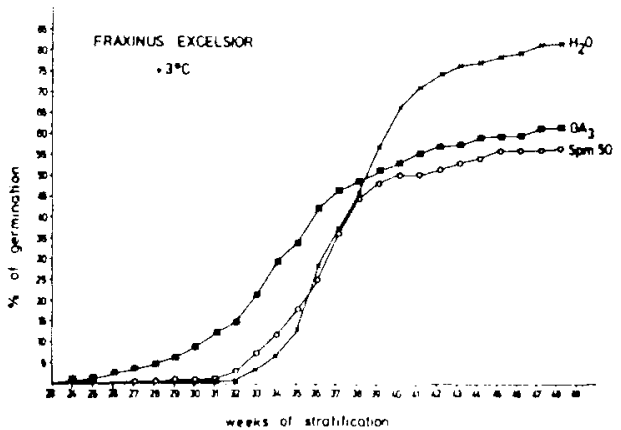

Fig. 6. Effect of spermine and gibberellic acid on dormancy breaking of $F$. excelsior seeds. Application before cold phase.

Figs. 5 and 6 show the influence of spermine and $\mathrm{GA}_{3}$ on dormancy breaking of $F$. excelsior seeds. The seeds were treated with either spermine or $\mathrm{GA}_{3}$ on one of two different dates before warm or before cold stratification. It was observed that, when these substances were applied before warm stratification, they were inhibitory throughout the whole period of dormancy breaking (Fig. 5). When applied before cold stratification, they were stimulatory during the first half of stratification and inhibitory of germination in the second half (Fig. 6).

\section{Discussion and Conclusions}

We think that the changes that we observed in polyamine and protein contents as well as in the response to exogenous treatments during dormancy breaking are connected with quantitative and qualitative metabolic changes related to particular phases of dormancy breaking. The results let us draw several conclusions: 1) changes in the polyamine level during dormancy breaking of $A$. platanoides seeds present different phases; 2) the maxima of the polyamine level precedes the maxima of EF-1 activity and protein synthesis; 3 ) the effect of exogenously applied substances depends upon the depth of dormancy of the treated seeds; 4) the more active stimulators of seed dormancy breaking in $A$. platanoides are, in order: $\beta$ hydroxyethylhydrazine, dicyclohexylammonium sulfate, spermine, kinetin and a mixture of spermine and kinetin; 5) it can be seen from the above data that spermine activity during dormancy breaking is similar to that of kinetin (A. platanoides) and GA (F. excelsior), which makes it possible to suggest a regulatory function for this polyamine.

\section{References}

Korcz A., Szczotka Z. \& Twardowski T. (1985) Elongation factor 1 in Norway maple seeds during the breaking of dormancy. J. Plant Physiol. 123, 317-326

Szczotka Z. (1984a) Polyamine changes in Quercus borealis Michx. and Quercus robur $\mathrm{L}$. seeds during aging in controlled conditions. Acta Physiol. Plant. 6, 127-135

Szczotka Z. (1984b) Difference in concentration of polyamines during the processes of afterripening seeds of Acer platanoides L. Acta Physiol. Plant. 6, 137-144

Szczotka Z. \& Tomaszewska E. (1979) Some metabolic processes accompanying dormancy breaking in the seeds of Norway maple. Arbor. Kornickie 24, 137-146 